\title{
Disclosing medical errors to patients: a status report in 2007
}

\section{Wendy Levinson MD, Thomas H. Gallagher MD}

I $\mathrm{n}$ the past decade, evidence has shown that adverse events, including errors, occur frequently in health care. An adverse event is defined by the Canadian Patient Safety Institute as "harm that results from an unexpected and unintentional occurrence in health care delivery." Some adverse events are preventable - these events can be called errors. Some errors do not cause harm to patients, either by chance or because the error was corrected before harm could occur; these are called near misses. Studies from multiple countries, including a Canadian study by Baker and colleagues, ${ }^{1-3}$ have estimated that adverse events affect up to $7.5 \%$ of patients admitted to acute care hospitals. Baker and colleagues estimated that $37 \%$ of those adverse events could be considered preventable. ${ }^{1}$ In response, leaders in the patient-safety movement have called for the system defects that underlie most errors to be corrected, as well as improvement in the recognition and reporting of errors and the disclosure of harmful errors to patients and their families.

Disclosing errors to patients is challenging for both physicians and health care institutions. ${ }^{4}$ Recent studies suggest that harmful medical errors are infrequently disclosed to patients and, despite a malpractice environment that is less onerous than in many countries, Canadian patients are no more likely to be informed about harmful errors than patients elsewhere..$^{5-8}$

\section{Rationale for disclosure of medical errors}

Physicians and health care institutions should support disclosure of harmful errors for both ethical and practical reasons. There presently is no consensus about whether to disclose near misses. From an ethical standpoint, patients require information about errors to make informed decisions about subsequent treatment. Thus, disclosure can be viewed as a part of the informed-consent process that enhances patient decision-making and autonomy. ${ }^{9}$ Disclosing errors also upholds the physician's ethical duty to tell the truth in the fiduciary physician-patient relationship. Although open communication with patients about errors is currently not a common practice, recent history suggests that the medical profession can improve its truth telling. Decades ago, patients were rarely told about serious diagnoses such as cancer, but in 2007 open disclosure of such information is standard. From a practical standpoint, research has demonstrated that patients want full disclosure of harmful errors but worry that health care providers will not do so. ${ }^{10}$ Finally, disclosure of errors, including near misses, creates an opportunity for patients to become part of quality-improvement efforts and can lead to improved patient outcomes. ${ }^{11}$ Patients can provide valuable insight and perspective about preventing future errors.

Despite the potential benefits of and the ethical rationale for disclosure, there is a "disclosure gap" between what patients want and what health care professionals commonly provide after an error has occurred. A 2002 survey found that disclosure of errors occurred in less than one-third of cases, falling short of patient expectations. ${ }^{5} \mathrm{New}$ research is shedding light on the factors that influence disclosure. A recent survey of physicians and surgeons in Canada and the United States suggests that the external malpractice climate may have less impact on doctors' attitudes toward disclosure than previously thought. Despite the considerable differences between the malpractice climates in the United States and Canada, doctors in both countries had similar attitudes toward disclosure. ${ }^{6,12}$ For example, the likelihood that a physician would support disclosing a serious or minor error to a patient was the same in both countries, despite the fact that Canadian physicians were far less worried about whether they were likely to be sued personally. In addition, physicians in both countries reported that they would provide similar information to the patient about the error, how it happened and what would be done to prevent recurrences.

Even when individual physicians favour disclosing errors that cause harm to their patients, additional barriers exist at the level of health care institutions, malpractice insurers and national health policy. In addition, few physicians receive any training in disclosing errors. However, important changes are happening to eliminate or reduce these barriers in Canada and in other countries.

\section{Recent changes that support disclosure}

Recent organizational, regulatory and legal changes support the disclosure of medical errors. The 2004 Canadian Medical Association Code of Ethics specifies, "Take all reasonable steps to prevent harm to patients; should harm occur, disclose it to the patient." ${ }^{13}$ The Colleges of Physicians in many provinces have similarly endorsed disclosure of adverse events. The Canadian Medical Protective Association endorses disclosure and offers disclosure-training workshops for physicians. ${ }^{14}$ The Canadian Patient Safety Institute is

Wendy Levinson is Chair and Professor of Medicine with the Department of Medicine, University of Toronto, Toronto, Ont.; Thomas H. Gallagher is Associate Professor of Medicine with the University of Washington School of Medicine, Seattle, Wash. 
presently developing national guidelines for the disclosure of adverse events. These guidelines will incorporate the perspectives of a broad group of stakeholders, including the Canadian Medical Protective Association and organizations that represent medicine, nursing, pharmacy and health care institutions. Legal requirements for disclosure of adverse events are also being created. As noted by Robertson, ${ }^{15}$ physicians have a common-law duty to disclose medical errors. He states, "Given that patients have a legal right to be told what may go wrong with proposed treatment, it must surely follow that they have the right to be told what has in fact gone wrong." ${ }^{15}$ Further, Manitoba and Quebec have recently passed legislation requiring that patients be informed of a critical incident or accident during their care. ${ }^{16,17}$ Although some provinces have not passed disclosure laws, many have developed provincial disclosure guidelines to assist health care workers and organizations. A further development is the emergence of apology laws. British Columbia recently passed a law that makes an apology for an adverse event inadmissible in court for the purposes of proving liability. ${ }^{18}$ Similar changes are occurring in the United States, where many states have adopted apology laws.

\section{Impact of disclosure on legal outcomes}

Concern about whether disclosing medical errors increases malpractice claims has been one of the main barriers to disclosure. Although concern about malpractice is a barrier in both Canada and the United States, it has been particularly important in the United States. Malpractice insurance premiums have increased substantially in the United States, and affordable liability insurance is unobtainable in certain geographic areas and specialties. ${ }^{19}$ As a result of this "malpractice crisis," some insurers and health care institutions have designed innovative programs that have challenged the conventional wisdom that disclosure will increase medical malpractice claims. Both the Veterans Affairs Medical Center ${ }^{20}$ in Lexington, Kentucky, and the University of Michigan Health System ${ }^{21}$ have developed programs to fully disclose errors and to provide appropriate financial compensation without patients having to file a malpractice claim. COPIC, a large Colorado malpractice insurer, has also implemented a program that encourages full disclosure and pro-

\section{Canadian views about disclosure}

- Canadian and US physicians have similar views about disclosure, despite different malpractice environments

- The Canadian Medical Association endorses disclosure

- The Canadian Medical Protective Association supports disclosure and offers training workshops

- The Canadian Patient Safety Institute, in collaboration with stakeholders, is developing disclosure guidelines

- Manitoba and Quebec have adopted laws that require disclosure of adverse events to patients

- British Columbia has adopted a law that prevents an apology from being considered an admission of liability vides patients with no-fault compensation. ${ }^{22}$ These organizations have all reported that these programs had a beneficial or neutral effect on their litigation experiences. The relative effect of disclosure versus compensation on the outcome of litigation is not possible to assess and the research is not definitive; however, there is emerging evidence that the number of malpractice claims may either stay the same or decrease after implementation of open-disclosure policies accompanied by financial compensation in appropriate cases.

\section{What is required for high-quality disclosure?}

Disclosing medical errors to patients may sound straightforward; however, it is actually a very challenging communication task. Most physicians have never been trained in what to say and how to say it. Research indicates that patients want to understand what happened and the implications for their care, and they want to receive a genuine apology from the physician. In addition, patients want to know that the health care professionals and the system will learn from the error to prevent a recurrence. ${ }^{10}$ Physicians need training about how to conduct an effective disclosure conversation. Educational programs, particularly those that incorporate standardized patients, can be effective for teaching physicians these skills. ${ }^{23}$

Institutional support is also needed for effective disclosure. It is essential that senior leaders in hospitals, including chief executive officers and board members, take responsibility for regularly reviewing medical errors and for creating policies related to disclosure. Progressive organizations are developing training courses for staff and providing roundthe-clock services to coach staff when disclosure is required. Despite a growing number of educational programs in Canada and elsewhere, there is little research on the effect of such programs on the skills of health care professionals, patient satisfaction or other outcomes.

\section{Conclusion}

The patient-safety movement has highlighted the importance of disclosing medical errors, and many organizations are developing policies and procedures to support these efforts. In Canada, new laws and guidelines are rapidly being developed. Australia, the United Kingdom, New Zealand and the United States have somewhat more experience in implementing programs to help health care professionals meet the challenge of disclosing medical errors. ${ }^{24-26}$ Physicians now have an opportunity to change the historical paradigm of never discussing medical errors with patients. The environment is clearly changing toward supporting physicians in effective and full disclosure. We anticipate that in the near future disclosing medical errors will be a routine part of medical care, allowing honest communication between health care professionals and patients, and facilitating quality improvement when things go wrong.

This article has been peer reviewed.

Competing interests: None declared. 
Contributors: Both authors contributed substantially to the conception and design and the drafting and revising of the article. Both authors gave final approval of the version to be published.

Acknowledgements: Thomas Gallagher is supported by grants from the Agency for Healthcare Research and Quality and the Greenwall Foundation Faculty Scholars Program.

\section{REFERENCES}

I. Baker GR, Norton PG, Flintoft V, et al. The Canadian Adverse Events Study: the incidence of adverse events among hospital patients in Canada. CMAJ 2004;170:1678-86.

2. Kohn LT, Corrigan J, Donaldson MS, editors. To err is human: building a safer health system. Washington: National Academy Press; 2000.

3. Leape LL, Brennan TA, Laird N, et al. The nature of adverse events in hospitalized patients. Results of the Harvard Medical Practice Study II. N Engl J Med I99I; 324:377-84.

4. Gallagher TH, Levinson W. Disclosing harmful medical errors to patients: a time for professional action. Arch Intern Med 2005;165:I8I9-24.

5. Blendon RJ, DesRoches CM, Brodie M, et al. Views of practicing physicians and the public on medical errors. N Engl JMed 2002;347:1933-40.

6. Gallagher TH, Waterman AD, Garbutt JM, et al. US and Canadian physicians' attitudes and experiences regarding disclosing errors to patients. Arch Intern Med 2006;I66:I605-II.

7. Schoen C, Osborn R, Huynh PT, et al. Taking the pulse of health care systems: Experiences of patients with health problems in six countries. Health Aff (Millwood) 2005; Suppl Web Exclusives:W5-509-25.

8. Coyte PC, Dewees DN, Trebilcock MJ. Medical malpractice - the Canadian experience. NEngl J Med I991;324:89-93.

9. Hebert PC, Levin AV, Robertson G. Bioethics for clinicians: 23. Disclosure of med ical error. $C M A J$ 200I;164:509-I3.

Io. Gallagher TH, Waterman AD, Ebers AG, et al. Patients' and physicians' attitudes regarding the disclosure of medical errors. JAMA 2003;289:100I-7.

II. Gallagher TH, Denham C, Leape LL, et al. Disclosing unanticipated outcomes to patients: the art and practice. J Pat Saf. In press.

I2. Gallagher TH, Garbutt JM, Waterman AD, et al. Choosing your words carefully: how physicians would disclose harmful medical errors to patients. Arch Intern Med 2006; 66 :I585-93.

I3. Canadian Medical Association. Code of ethics. Ottawa: The Association; 2004 Available: http://policybase.cma.ca/PolicyPDF/PDo4-o6.pdf (accessed 2007 May 7).

4. Beilby W, Wallace G. Disclosing adverse events to patients: strengthening the doctor-patient relationship. Ottawa: Canadian Medical Protective Association; 2005

I5. Robertson G. When things go wrong: the duty to disclose medical error. Queens LaW J 2002;28:353-62.

16. The Regional Health Authorities Amendment and Manitoba Evidence Amendment Act. SM 2005, c24. Available: http://web2.gov.mb.ca/laws/statutes/2005/c02405e .php (accessed 2007 May 7 ).

I7. An Act to amend the Act respecting health services and social services as regards to the safe provision of health and social services. RSQ 2002, Bill II3, c 7I. Available: www2.publicationsduquebec.gouv.qc.ca/dynamicSearch/telecharge.php?type $=5 \&$ file $=2002$ C7IA.PDF (2007 May 7).

I8. Apology Act. RSBC 2006, Bill I6. Available: www.leg.bc.ca/38th2nd/amend/govi62.htm (accessed 2007 May 7).

I9. Mello MM, Studdert DM, Brennan TA. The new medical malpractice crisis. $N$ Eng JMed 2003;348:228I-4.

20. Kraman SS, Hamm G. Risk management: extreme honesty may be the best policy Ann Intern Med I999;13I:963-7.

2I. Clinton HR, Obama B. Making patient safety the centerpiece of medical liability reform. N Engl JMed 2006;354:2205-8.

22. Gallagher TH, Studdert D, Levinson W. Disclosing harmful medical errors to patients. NEngl J Med 2007;356: 2713-9.

23. Chan DK, Gallagher TH, Reznick R, et al. How surgeons disclose medical errors to patients: a study using standardized patients. Surgery 2005;I38:85I-8.
24. Australian Council on Safety and Quality in Health Care. Open disclosure standard: A national standard for open communication in public and private hospitals following an adverse event in healthcare. Canberra: Commonwealth of Australia 2003. Available: www.safetyandquality.org/internet/safety/publishing.nsf/Content /F87404B9BooD8E6CCA257IC60oooFo49/\$File/OpenDisclosure_web.pdf (accessed 2007 May 7).

25. Kalra J, Massey KL, Mulla A. Disclosure of medical error: policies and practice. $J R$ Soc Med 2005;98:307-9.

26. Bismark M, Dauer E, Paterson R, et al. Accountability sought by patients following adverse events from medical care: the New Zealand experience. CMAJ 2006; I75:889-94.

Correspondence to: Dr. Wendy Levinson, Department of Medicine, University of Toronto, 3-805, I9o Elizabeth St., Toronto ON M5G 2C4; fax 4I6 978-7230; wendy.levinson@utoronto.ca

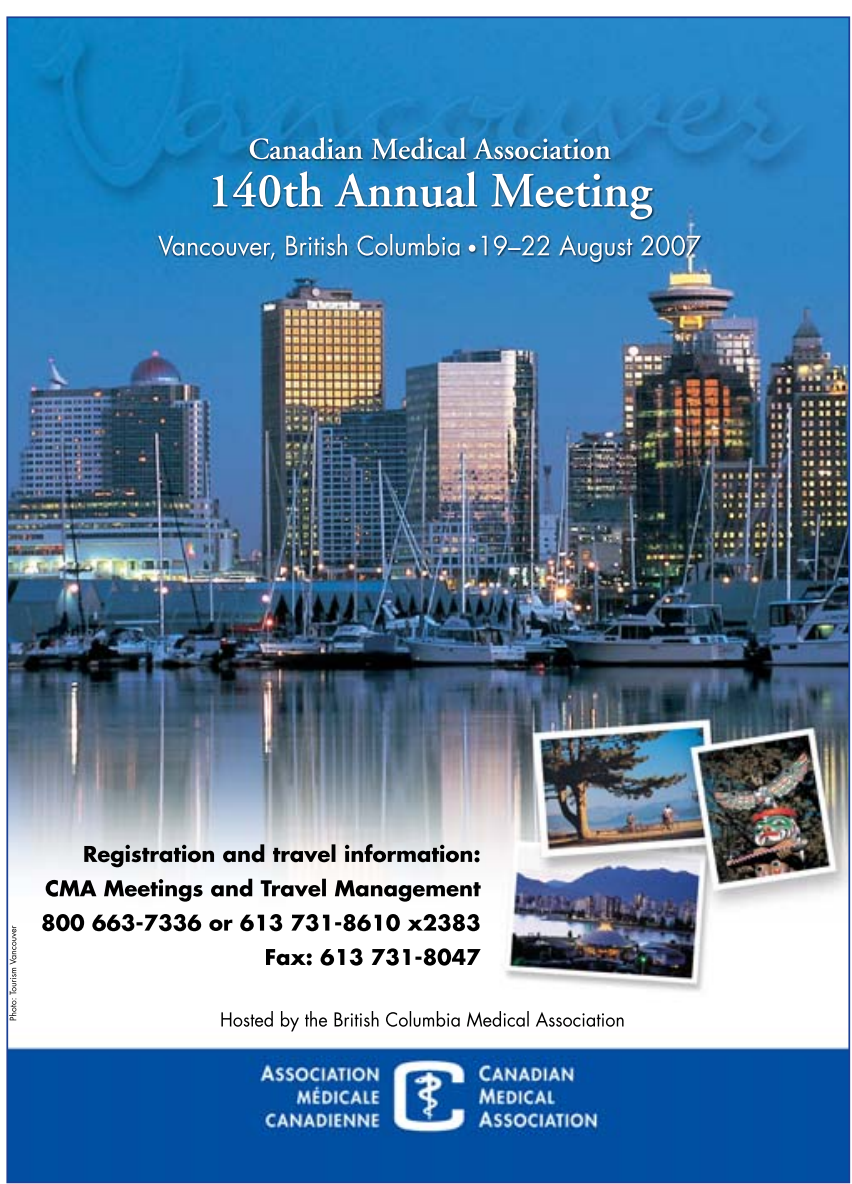

